Post-print: Accepted for publication in Health and Social Care Chaplaincy

\title{
Healthcare Chaplaincy and Spiritual Care for Trans People: Envisaging the Future ${ }^{1}$
}

Dr Susannah Cornwall, Department of Theology and Religion, University of Exeter

\begin{abstract}
$\underline{\text { Abstract }}$
Spiritual care has the potential to mitigate against "gaps" left when waiting lists (and times) for NHS gender identity clinics (GICs) spiral, and trans people awaiting medical interventions are at increased risk of suicide and self-harm. Healthcare chaplaincy has an explicit role to play, particularly for the sizeable number of trans people with religious faith or who struggle with finding support from faith communities. Spiritual care should be integrated within direct care provided by healthcare professionals, with additional care from specialist chaplains where desirable. Findings from the Modelling Transgender Spiritual Care project point to a need for additional training and resourcing in gender identity care for spiritual carers; a new prioritization of healthcare chaplaincy for gender identity services, which has implications for budgets and commissioning; and increased accountability for fulfilling the statutory requirement for spiritual care in the NHS.
\end{abstract}

$\underline{\text { Key words }}$

Transgender, spiritual care, chaplaincy, gender transition.

\section{Introduction}

Faith-based groups in Britain provide health and social care in areas including dementia, perinatal care, obesity and diabetes, loneliness and social isolation, accident and emergency care, and mental health. In some cases these are specifically understood to plug gaps in National Health Service (NHS) care caused by funding cuts (Slawson 2018; Cinnamon Network 2018, 2). One perceived advantage of such initiatives is their low cost, being reliant primarily on volunteer labour (Simmons 2018, 8; 12), thereby saving the NHS money; however, additionally, by foregrounding spirituality and faith, they might be understood as holistic, promoting community and belonging (Simmons 2018, 12), boosting service users' wellbeing.

In some respects, such initiatives return to an older model in which spiritual and medical care were more integrated, and churches were direct providers of para-medical and para-social services to local communities. Indeed, such integration between welfare and religion is still more common elsewhere in Europe, as Grace Davie, Anders Backström and colleagues found in the

\footnotetext{
${ }^{1}$ I am grateful to Simon Harrison and Robin Pfaff for their incisive comments and invaluable feedback on a draft version of this paper, and to Tessa Crossley for research assistance.
} 
Welfare and Religion in Europe Project and the Welfare and Values in Europe Project in the 2000s (Davie, 2012; Davie, 2015). In Britain, however, especially as healthcare chaplaincy services have been eroded, it has become increasingly difficult to persuade critics of the value of the presence of faith-based care, and prioritizing spirituality within the health service. .

In this paper, drawing on findings from the Modelling Transgender Spiritual Care (MTSC) project, ${ }^{2}$ I discuss care for trans people, particularly those receiving medical care for transition from NHS gender identity clinics (GICs). In this case, too, spiritual care in general, and chaplaincy more specifically, has the potential to mitigate against "gaps" left when waiting lists (and times) spiral, and people awaiting medical interventions are at increased risk of suicide and self-harm. Healthcare chaplaincy has an explicit role to play, particularly for the sizeable number of trans people with religious faith or who struggle with finding support from faith communities. A "bothand" approach is necessary, with spiritual care integrated within direct care provided by healthcare professionals, and additional care from specialist chaplains where desirable. I show that this has implications for those responsible for commissioning in gender identity services and that a new prioritization of healthcare chaplaincy is required.

\section{Context}

A huge increase in referrals to NHS GICs in the last decade means waiting times for assessment and treatment habitually exceed the mandated 18 -week waiting period, sometimes by over a year (Healthwatch 2015). Long waiting times after initial referrals to GICs adversely affect trans people's mental health (Hudson-Sharp and Metcalf 2016, 39-40; 59). Pre-intervention, trans people are at significantly increased risk of mental health problems, suicide and self-harm, and trans people with mental health problems are less likely than non-trans people to receive appropriate care. (McNeil et al 2012, 27-28, 59; Haas, Rodgers and Herman 2014).

Anecdotal evidence suggests a significant proportion of people seeking gender reassignment within the NHS in England have a personal faith, and that faith and spirituality are impacted (positively or negatively) by gender incongruence and transition. This may relate to factors external to affected individuals but might also arise from minority stress and internalized transphobia. For many people, spirituality - especially the sense of something beyond the self, possibly an ultimate reality, life force or creative principle - is important as they await or undergo

\footnotetext{
${ }^{2}$ The project was funded by the Sir Halley Stewart Trust. The empirical research received ethical approval by the South West - Exeter Research Ethics committee and the Health Research Authority (IRAS number: 235694).
} 
medical interventions and experience challenging life changes. For people of faith, religious communities may rally round with practical help, and offer spiritual support such as prayer. But some trans and nonbinary people have found it difficult to find affirming religious communities. Some trans people in the earlier stages of transition may encounter opposition to their presenting and dressing in their gender of expression within their religious community. Feelings of alienation from the community, or from God, may exacerbate loneliness and guilt in people suffering with depression (Swinton 2001, 167). This is problematic given the importance of being accepted and valued for most individuals.

Existing work on care and wellbeing for trans people (e.g. McNeil et al 2012) does not address the imperative for spiritual care identified by the Care Quality Commission (as part of the Health and Social Care Act 2008 [Regulated Activities] Regulations 2014). ${ }^{3}$ This is unlikely to change spontaneously in a climate where healthcare chaplaincy services are increasingly eroded (Swift 2014). Spiritual care and healthcare chaplaincy are not identical, but chaplains have often proven to be vocal advocates for the place of spirituality in healthcare. To date there have not been comprehensive strategies in place for linking people in transition with appropriate spiritual care before and during their care from NHS GICs, nor for ensuring specialist chaplaincy services are available where appropriate: this was a lack that the Modelling Transgender Spiritual Care (MTSC) project aimed to address.

\section{Healthcare Chaplaincy and LGBT Affinities}

Wilfred McSherry has been influential in his conviction that spiritual care is neither the remit only of chaplains, nor something which exists only for people who profess a religious faith. For McSherry, spiritual care is intimately related to care more broadly and is most effectively provided by nursing professionals, who might well have no special interest of expertise in religious faith specifically (McSherry 2007). The NHS Contract of Care makes clear that spiritual care is for everyone (i.e. those of any faith or no faith): if spiritual matters are taken into account across care,

\footnotetext{
${ }^{3}$ The Health and Social Care Act 2008 (Regulated Activities) Regulations 2014 at regulation 9(3)a states that "Assessments of people's care and treatment needs should include all their needs, including ... religious and spiritual needs" (http://www.legislation.gov.uk/ukdsi/2014/9780111117613/regulation/9). Similarly, the NHS Contract of Care 2017-18 states that "The Provider must take account of the spiritual, religious, pastoral and cultural needs of Service Users" (NHS England 2018, clause 14.1), and that "The Provider must have regard to NHS Chaplaincy Guidelines" (ibid, 14.2). However, there are (as far as we know) currently no guidelines or frameworks in use by NHS England to ensure trans people's spiritual care.
} 
this is all to the good. That said, however, trans people who do have a faith - or are negotiating relationships, perhaps tense ones, with religious communities, friends or relatives - might benefit from care given by a chaplain better equipped to address such issues than a member of the core healthcare team. McSherry notes that competence in spiritual care necessitates practitioners' recognition of their own understandings (and, perhaps, limitations) of the spiritual dimension (McSherry 2010: 62): it will be important for healthcare professionals working with trans people to refer to chaplains where appropriate.

That said, some healthcare chaplains themselves lack confidence that they have been adequately trained or resourced to work sensitively and effectively with trans patients. Provision for ongoing specialist training on trans as an aspect of healthcare chaplains' continuing professional development is desirable. However, many healthcare chaplains do already have expertise in the area and close affinities with trans and other LGBT people. Furthermore, there may be respects in which healthcare chaplaincy roles are particularly appealing to ministers inclined to trans inclusion. In some sense, healthcare chaplains may fly under the radar and be able to exercise more pastoral and liturgical creativity than clergy in other contexts.

Church of England chaplains, for example, comments Christopher Swift, sometimes feel remote from the broader denomination. Chaplains may feel insufficiently supported, and uninvolved in broader conversations, and chaplaincy services may be cut in times of financial straitening (Swift 2014, 159); on the other hand, however, "Standing outside Church employment, hospital chaplains occupy a position which enables them to ask searching questions about the Church's public stance on issues such as human sexuality" (Swift 2014, 161). Indeed, he remarks, there may be a higher proportion of non-heterosexual clergy in chaplaincy roles than in parish ministry precisely because these ministers are in some senses in exile from the hierarchy. Christina Beardsley was already a healthcare chaplain when she underwent gender transition in 2001, and notes that she received support from her NHS manager but opposition from the Church of England bishop. She also notes that chaplaincy afforded better privacy and work-life boundaries than parish ministry, particularly important as she was working through questions of gender identity (Beardsley 2018; Cambridge Festival of Ideas 2015).

This chimes with Swift's findings (Hancocks, Sherbourne and Swift 2008) that a relatively high proportion of Church of England healthcare chaplains are gay men in "retreat" from other structures, and may consider themselves "refugees". These studies did not look at trans-identified clergy in particular, nor the implications for trans and nonbinary patients, but conceivably chaplains who have themselves felt alienated from religious structures and even communities might demonstrate particular sensitivity to trans patients. 


\section{Healthcare Chaplaincy, Health and Hope}

Healthcare chaplaincy services have been eroded in recent years, and may continue to be an easy target for those managing stretched healthcare budgets. However, where healthcare chaplaincy works well, it might be understood, as by John Swinton and Ewan Kelly, as promoting holistic healing and wellbeing. Health is not just an absence of illness, but involves promoting "those things that enhance resilience and increase capacity" (Swinton and Kelly 2015, 181). This is significant when considering chaplaincy for transgender spiritual care, since, although GICs in Britain usually sit within mental health care frameworks, many trans people do not consider their identity an illness or pathology, and may resent the medicalized pathway through which they must go to access therapies.

Following Wendell Berry (2002), Swinton and Kelly suggest that health might, rather, be understood as "membership".

It has to do with feeling at home with one's true self irrespective of one's circumstances and recognising that one exists in and is a part of a context or a story that is greater than one's self. Healing relates to the means by which such well-being is achieved. Spiritually, health ... relates to the ability to hold on to who you are and why you are in the world even in the midst of difficult circumstances and sometimes unbearable suffering. (Swinton and Kelly 2015, 181)

In this way, therapeutic chaplaincy means helping people to overcome disconnection: from themselves, their communities (including religious communities), and God. Berry's focus is on membership as belonging with a community, but we might of course press the metaphor further and reflect on membership as reconciliation with one's own body. For some religious commentators, like Mark Yarhouse, the assumption is that reconciliation necessitates acceptance of the God-givenness of one's body, and for trans people to "resolve dysphoria in keeping with their birth sex" (Yarhouse 2015, 137); this reinforces the common misperception that all trans people suffer gender dysphoria, and echoes earlier Christian accounts of transgender as a kind of Gnosticism, a desire to transcend the body and somehow float free of it - not an option open to incarnate persons (Archbishops' Council 2003, 249). But reconciliation might just as well be understood as promoting harmony between the members such that individuals do not feel alienated from their bodies. Such feelings of alienation may stem from "implicit" dysphoria, but might be prompted by internalized transphobia, or abuse or violence on the basis of unusual physical appearance. 
Swinton and Kelly also appeal to the recovery model of health, which refers to the capacity to pursue meaning and purpose even whilst continuing to experience mental health problems (Swinton and Kelly 2015, 182). This resists the notion that some mental health conditions are simply incompatible with meaning-making and hope, and is significant given some religious commentators' belief that trans people can never find fulfilment whilst continuing in their trans identity, but must "overcome" it, making peace with their "true" identity. For Swinton and Kelly, "mental health is not the absence of illness, but the presence of meaning, identity and hope" (Swinton and Kelly 2015, 182).

\section{Modelling Transgender Spiritual Care Project (MTSC): Some Initial Findings}

Despite the fact that all NHS patients have the right to appropriate care taking into account their spiritual, religious and cultural needs, it is clear from the MTSC project that this does not always happen. Spiritual care might, however, be especially helpful in GIC contexts, and there are, I suggest, particular imperatives for commissioning specialist chaplaincy services given that significant numbers of trans people have a faith and may struggle to find "safe" religious communities.

In 2018 I undertook a small qualitative study in partnership with an NHS GIC in England, which asked current patients, and others who had completed their transition, about their experiences of receiving spiritual care and their ideas about what would constitute good spiritual care. Fifteen participants were recruited: some current patients of the clinic, some former patients of the clinic, and some who had transitioned via other clinics. Current patients of the clinic were recruited via publicity distributed by the clinic, including an email mailshot to current patients, and posters displayed in the waiting area. Former patients and other trans people were recruited via snowball (chain-referral) sampling.

All respondents filled in a questionnaire capturing responses to questions about their spiritual or religious affiliations, if any; whether they had spoken to a spiritual or religious leader or mentor before or during transition; whether any such conversations had been useful and why; whether spiritual or religious matters had formed any part of respondents' conversations with friends and family about gender identity and the possibility of transition; the nature and range of spiritual activities, if any, that respondents had undertaken before or during transition; whether any healthcare professionals had asked if they would like spiritual or religious support; whether respondents had ever been offered an opportunity to speak to a healthcare chaplain or spiritual carer about their thoughts and feelings surrounding transition, and why they might or might not have accepted the offer; what activities and events might in respondents' view have a positive 
effect on the spiritual wellbeing of people going through transition; how, in respondents' view, spiritual care might best be provided for people transitioning with NHS gender clinics in England; and whether, in respondents' view, there were currently any barriers to the provision of good spiritual care for people transitioning with gender clinics in England.

The questionnaire data were manually coded via structural coding (for example, identifying positive versus negative experiences of conversations with spiritual carers) and values coding (to reflect respondents' worldview and attitudes toward experienced or potential spiritual care), organized by theme, and analysed via reflection on both the common and conflicting meanings that arose and the implications for changed practice. The small sample size meant that it was not possible reliably to analyse, for example, differences in attitude toward spiritual care based on professed spiritual or religious affiliations (if any). However, respondents across a range of faith traditions and none recognized spiritual care's significant potential to impact on trans people's wellbeing and outcomes, with the caveat that spiritual care done badly risked doing harm.

The project was a form of action research, seeking to transform existing practice. It aimed to highlight shortcomings in existing provision for trans people and make constructive suggestions for revised practice. It drew on expertise from trans people themselves, non-trans (cisgender) allies, and those who had worked with trans people as healthcare chaplains, gender medicine specialists, counsellors and others. It was phenomenological and its interpretation was closely grounded in the concerns of those most directly involved. Simultaneously, it brought critical distance: the lead researcher, an ally but not a member of the trans community nor involved in providing healthcare for trans people, could facilitate interactions between groups who had sometimes felt wary of one another.

In general, participants were positive about the concept of spiritual care, and did not query the use of the term "spiritual" itself. Concerns were raised about the challenges of providing good spiritual care, not whether spiritual care was worthwhile as such. One respondent, Rachael, said she did not identify with any particular faith but felt that "spiritual help and guidance for a transgender person with faith would be a wonderful comfort and support". However, she noted that well-meaning but misguided care could do more harm than good. She recounted her experience of receiving Christian ministry as part of a debt counselling programme:

Prayers were conducted in which I asked Jesus to forgive my sins. I found it hard not to see this as forgiving myself for being transgender. It almost felt like more guilt was being added for me to 
manage. I know this was not the intent but shows how kindly uninformed involvement at a stressful time can complicate things. (Rachael, no religion) ${ }^{4}$

Another participant, Holly, was Christian but feared that spiritual care could be a means of imposing non-trans-accepting religion onto people undergoing transition. Previous bad experiences meant she would not have taken up any offer of spiritual care: "It's more a mistrust of the established church than anything else. When acceptance is grudging, conflicted, and halfhearted I can't but feel their succour is a 'fop'. There would need to be radical declarations of wholehearted acceptance to shake my scepticism." Some respondents drew on their own expertise as spiritual supporters to others. Pererin, who had received spiritual care during transition and had since gone on to provide such care to other trans people as an ordained minister in a Christian denomination, concurred that

A gentle approach is advisable, as many have found religion to be a source of abuse as much as, or more than, a source of support. It is necessary to educate chaplains very well, for instance, as it can be hard for them to understand the pain that they can put people through even with well-meaning ignorance. Spiritual care is a great responsibility with a deep effect on people's mental health, and must not be treated lightly, or without preparation. (Pererin, Christian)

Many people undergoing transition remain under GIC care for a considerable time before and after medical or surgical interventions. Sometimes former patients go on, once discharged, to mentor and accompany current patients. Some respondents identified longevity and continuity of care as potential challenges: Rachael noted that, ideally, spiritual care would be available long-term, and those who provided it equipped to deal with the complexity and difficulty some trans people experienced when negotiating their identity and place in their community:

Most of us experiencing transition have an emotional age of a child when we transition and have to grow up again, many without the support of friends or family. If spiritual care is to help bring that sense of family for us, it needs to recognise the responsibility it brings. Many of us need desperately to find a touchstone that we can cling to when all around us is changing. We ourselves at this time can be difficult and display inappropriate and childish behaviour. Our journey is not easy and being a friend for us is not easy. (Rachael, no religion)

\footnotetext{
${ }^{4}$ All participants' names have been pseudonymized. Participants were given the opportunity to choose their own pseudonym.
} 
McSherry, similarly, remarks that spiritual assessment should be ongoing because spiritual needs may develop and change over time (McSherry 2010: 62). This makes the challenges posed by insufficient funding for healthcare chaplains' time even more pressing.

Whilst some responses indicated that spiritual care was best provided by chaplains or other professional ministers of religion, participants were asked about whether they would also like, or would have liked, conversations about spirituality and faith with their healthcare professionals. One respondent, Virginia, had been considering Christian priesthood for some time, and said,

I once discussed my perceived sense of calling to ordination with the psychiatrist at my gender clinic who seemed interested and mildly encouraging that I should pursue this but nobody else within the medical profession ever discussed this with me. I was left feeling that in order to transition, I had to lose everything and everyone I held dear or still dreamed of for the future. This is ultimately what has happened. (Virginia, Christian)

The perceived loss of Virginia's vocation occurred partly because of unsupportive responses from Christians, including those involved in the discernment process with power over whether she be recommended for ministerial training. However, there was also an implication that Virginia's medical team had been unable to help her negotiate holding together faith and gender identity. Furthermore, Virginia suggested spiritual care could complement broader medical care and lead to improved outcomes. She felt the erosion of healthcare chaplaincy and spiritual care in an increasingly secularized Britain had exacerbated some trans people's mental health problems: "I don't think it is a coincidence that many transgender people struggle with mental ill-health including depression as I have. This increasing burden on the NHS could be relieved enormously if there was better provision for the spiritual well-being of all who identify as transgender." The National Institute of Economic and Social Research's 2016 review of evidence of inequality toward LGBT people in Britain noted that how experiences of inequality varied according to religion remained understudied (Hudson-Sharp and Metcalf 2016, 118): tellingly, inequality perpetuated by faith groups or experienced by trans people of faith was not part of this review, suggesting that religion and spirituality's significance and potential impact on wellbeing were overlooked.

It is not obvious how or why healthcare professionals who claim no particular expertise in spirituality should be expected to provide spiritual care. Whilst Virginia and some other respondents were positive about the idea of having discussions on spirituality with their professional medical team, others were more circumspect. Erdo said, "I can only see this being helpful if the medical team know enough about the person's faith to be able to engage usefully in that discussion - and then only if they're definitely going to be supportive of the trans person's 
experience as a priority." Erdo, a Buddhist, noted that they had frequently experienced "barelyconscious transphobia" within their minority tradition. So training to ensure good spiritual care might need to include both general training on spirituality, and more specific knowledge about and links to particular faith traditions where appropriate. It might also mean training in appropriate triaging and referral onward: in a GIC, for example, there might be one healthcare professional with overall responsibility for spiritual care oversight, able to "buy in" specialist chaplaincy services as appropriate, and refer patients to faith communities and support beyond the service itself.

Some respondents suggested authority and prestige historically attached to status as a medical professional, despite having been challenged in recent years via patient-centred and nonpaternalistic accounts of care, could also be used positively. Erdo felt medical professionals working with trans people should advocate for them with faith communities, noting that members of some faith groups "are more willing to listen to medical professionals regarding the validity of both binary and non-binary gender experience".

Respondents were asked what they believed were the barriers, if any, to the provision of good spiritual care for people going through transition with NHS clinics. Their responses chime with problems which the MTSC project had already identified as potential issues, including lack of funding or will to commission specialized chaplaincy services; an absence of confidence among medical staff in discussing spirituality and faith; and sparse awareness of trans issues among faith leaders:

I never received any information about spiritual care at all, nor have any of the people I supported mentioned such information. If there are any other barriers, I suspect they lie in lack of education both among medical professionals regarding spiritual care, and among religious professionals regarding gender identity. (Pererin, Christian)

Possibly the main barrier if there is one is the lack of proactively asking whether a service user could use this kind of support, and the ability to provide it (or provide access to it) if their answer is yes. (Erdo, Buddhist)

The service [my NHS GIC] provides has been changed recently and driven by budget requirements. In other words the funding is not available now for 'non essential services.' I think a 'Spiritual Care Service' essential. However I am sure funding would be a challenge. (Rachael, no religion) 
These might all be understood as structural issues: a current lack of foregrounding of spiritual care in medicine generally, exacerbated by budgetary constraints; consequently, a lack of comprehensive proactive provision of spiritual care; and an absence of joined-up systems ensuring accountable oversight of spiritual care.

Additionally, one respondent suggested links between the perceived position of some Christian churches and the reception of trans people within other institutions: "If the Church of England is cold-hearted towards transgender people as they have been and to a point in a national sense still are, then so will the NHS, the legislature, government and society as a whole be" (Virginia, Christian). Whilst, historically, many salaried healthcare chaplaincy posts were Church of England clerical positions, the healthcare chaplaincy field is now far more diverse, with a range of lay and ordained, salaried and non-stipendiary, full- and part-time chaplains of various faith traditions, as well as Humanists. The Church of England's authority to influence societal opinion identified by Virginia may, if it ever existed quite like this, be firmly on the wane.

Nonetheless, for some respondents, the Church of England's status as the established church remained significant. Holly commented, "I still see the pillars of society as church, government and the law. In my view to be truly accepted you need to be embraced and protected by all three". Indeed, Holly had had extensive communications with her local Church of England diocese explaining how important it was for her to be acknowledged in her gender identity by the church, and had enquired about the possibility of rebaptism in her new name. A diocesan representative explained that a second baptism would not be possible, since baptism was a onceand-for-all unrepeatable entry into Christian faith. Holly responded that, whilst she understood baptism was a marker of entry into the community rather than a "naming" ceremony, nonetheless the juxtaposition of name and welcome was a very strong statement of identity. Recognition by the church of her identity would, she said, allow her to reclaim the foundations of her life as truly her own, not something "borrowed". They agreed between them that, whilst no second baptism could occur, once Holly had received her Gender Recognition Certificate she would also be issued with a baptism certificate reflecting her preferred name. Holly says, "It is a much cherished piece of paper which alongside my Gender Recognition Certificate, birth certificate and degree certificates gives outward 'social' validation of my identity". Nonetheless, Holly feels that the Church of England's failure to explicitly welcome and affirm trans people - the bishops declined to commission specific liturgical materials to mark gender transition following the passing of the General Synod motion of July 2017 which called consideration of their provision - was destructive: "Their reluctance to make a universal declaration of the acceptance and rights of those parishioners 
leaves the door open for transgender people to leave". ${ }^{5}$ Furthermore, in a context where around 12 per cent of trans people have had or been offered conversion therapy, and where most conversion therapy is conducted or offered by faith groups, ${ }^{6}$ it might be even more important for the established church to lead by example, sending a clear message of unambiguous welcome.

\section{Trans Spiritual Care Without Borders}

Participants' responses suggested that, overall, the concept of spiritual care was considered worthwhile, and that, although its provision would need careful execution, would potentially be an important means of support and the affirmation of identity for people undergoing transition. Participants' hesitations about how this might work in practice tended to focus on questions about appropriate training, resourcing, and mechanisms for protecting trans patients from well-meaning but misinformed care which could be tacitly or explicitly harmful to their wellbeing.

\footnotetext{
5 The "Blackburn motion", proposed by Revd Chris Newlands, passed in all three houses of the General Synod. It read, "That this Synod, recognising the need for transgender people to be welcomed and affirmed in their parish church, call on the House of Bishops to consider whether some nationally commended liturgical materials might be prepared to mark a person's gender transition". The House of Bishops did subsequently consider the request, but concluded that no such new materials were necessary: in January 2018, a statement signed by William Nye (secretary to the House of Bishops) stated that, if trans people asked to have their transition marked during worship, "Baptism and confirmation are the normative ways of marking a new or growing faith in Jesus Christ. If the enquirer is already baptized and confirmed, the House notes that the Affirmation of Baptismal Faith, found in Common Worship [a collection of authorised Church of England liturgy], is an ideal liturgical rite which trans people can use to mark this moment of personal renewal" (House of Bishops 2018). Rob Clucas critiques the longer statement, holding that the House of Bishops' desire to treat trans people equally (by not commissioning specific liturgy for marking transition but rather commending existing liturgies) actually disadvantages them, and that whilst the House of Bishops may consider the existing liturgies “ideal", they are clearly not seen this way by many trans people (Clucas 2018, 4-7). Clucas also characterizes the statement as a missed opportunity for the House of Bishops to exercise leadership, and "an abdication of responsibility ... for the Church to act justly towards trans people" (Clucas 2018, 10).

${ }^{6}$ Government Equalities Office 2018, 83-94. For 49 per cent of trans respondents who had undergone or been offered conversion therapy, this was by a faith organization or group (as opposed to healthcare providers, family members or others). Of those trans people professing a faith, 16 per cent of Christians, 16 per cent of Buddhists, 25 per cent of Jews, and 43 per cent of Muslims had either received or been offered conversion therapy, compared with 11 per cent of those with no religion (Government Equalities Office 2018, 92).
} 
In light of these initial findings, a research group meeting was convened at the University of Exeter in 2018, bringing together trans people, healthcare chaplains, academic scholars of religion, and healthcare practitioners. This group also discussed perceived barriers to spiritual care, and potentials for spiritual care, for people undergoing transition, in light of some of the initial responses. The group comprised people from Buddhist, Christian, Jewish and Muslim communities, and those of no religious affiliation. The group operated independently from the clinic and based their recommendations on their own personal and professional experience.

The group first considered how good spiritual care for trans people might look without constraints of time, money or resources. They next considered barriers to making this happen; what would need to take place to remove or mitigate these barriers; and the limiting and facilitating mechanisms.

How should good spiritual care look?

- Non-hierarchical, but with appropriate boundaries to safeguard the wellbeing of those involved.

- Provided by chaplains properly trained and resourced to meet and understand people from various religious and non-religious perspectives.

- Training should familiarize chaplains with trauma theory and the ways in which trans people might experience ongoing trauma.

- Training should draw on and allow chaplains to become "multi-lingual" in medical, cultural/social, and critical theory perspectives, as well as engaging with personal testimonies.

- Training should involve resourcing chaplains to understand a range of religious perspectives and their rationales for objections to trans identity, gender confirmation surgery, and related issues.

- These chaplains should be able to follow patients between care settings and over a period of time as appropriate, to understand the full context and situation under discussion holistically.

- The chaplains, and any other professionals involved in providing spiritual care, should be able to individualize it as appropriate for each patient: the model should not be "one size fits all"'.

- Ideally, spiritual care would be available not just for those already undergoing transition under the care of a specialist GIC, but for all who identify as transgender in all their medical care. 
- For those who do transition, it should involve spiritual accompaniment from the earliest stages. Early referrals to spiritual carers could go some way to plugging the "mental health gap" in NHS gender services (exacerbated by long waiting lists for treatment).

- The resources on offer should include a list of safe spiritual contacts across the country. (The group noted that the coverage of GICs in England is patchy, and that patients sometimes have to travel very long distances to a clinic. Patients might not be willing or able to travel just to see a chaplain, so ideally they would be able to be put in touch with a safe contact local to them.)

- This should include a database detailing and signposting to peer support groups, faith communities and religious professionals. (There would be challenges to ensuring any such database remained current, and to undertaking appropriate "gatekeeping" to ensure that congregations listed really were safe spaces for trans people.)

- Spiritual care relationships should be able to continue long-term even after discharge from gender medicine services, since the spiritual healing process may go on long after the association with the GIC.

- There should be a means for providing doctrinal support from within various faith communities to help combat anti-trans rhetoric and religious objections to trans people.

- Spiritual caregivers should also be well-equipped to advise trans people on broader issues such as equalities legislation, workplace and housing rights, and to be able to signpost to practical assistance.

One example of such good practice is Sojourn Chaplaincy, which provides multifaith spiritual care at Zuckerberg San Francisco General Hospital in California, and has been trialling training in gender diversity for chaplains. This was in response to a change in Californian law in 2013 which prohibited health insurance companies from excluding trans patients, and meant many more trans people entered the hospital system (Sojourn Chaplaincy 2017).

The group recognized the need to ensure that any centralized resources on working with and safeguarding the wellbeing of trans people were made available to all those involved in spiritual care and accompaniment (such as former patients who provided semi-official mentoring and befriending services via GICs), not just salaried healthcare chaplains. The group also emphasized that spiritual care is the responsibility of all NHS staff who work with patients, which includes recognizing patients' spiritual needs and referring them to more specialized services as appropriate. (As I have noted above, there is a case for additional specialist chaplaincy support for trans people, 
especially people of faith.) The NHS might itself also have a role in the education of faith communities and in advocacy.

The group also identified a need to be able to identify any anti-trans chaplains, and ensure appropriate gatekeeping for trans patients' protection. This would entail accountability and oversight by senior chaplains, perhaps one in each region or one linked to each NHS GIC. However, they also noted (as discussed above) the high proportion of LGBTQ people working as Christian healthcare chaplains. While there might be some advantages to having trans-identified chaplains, there were also potential issues stemming from internalized transphobia among trans chaplains, and the need for ongoing therapy for chaplains.

Next, the group considered current barriers to the provision of good spiritual care:

- Overall funding constraints for the NHS, and the dynamics surrounding the allocation of funding within the NHS. This included battles between professionals for money and resources; and a perception that spiritual care in general, or healthcare chaplaincy more specifically, were niche or low-priority areas.

- Transgender is often deemed to fall within the mental health area of the NHS, which already carries significant stigma and may be further eroded in terms of the importance it is given. ${ }^{7}$

- Widespread low-level transphobia might explain poor funding for GICs, whose waiting lists are increasing monumentally, making waiting times much longer than in many other areas of the health service.

- There might be internal resistance from within faith traditions: some existing healthcare chaplains might be unwilling or unable to provide positive care for trans people.

- Sometimes there was ongoing sadness and grief for chaplains when patients moved on: this might be particularly acute when the chaplain had accompanied a patient through an intense period during which gender transition had taken place.

\footnotetext{
7 The NHS adult GICs in England each fall under specific mental health care trusts rather than more general, acute, emergency or other specialist trusts. They are: Charing Cross GIC, London (Tavistock and Portman NHS Foundation Trust); Leeds GIC (Leeds and York Partnership NHS Foundation Trust); Northampton GIC (Northamptonshire Healthcare NHS Foundation Trust); Northern Region Gender Dysphoria Service, Newcastle (Northumberland, Tyne and Wear NHS Foundation Trust); Nottingham Centre for Gender Dysphoria (Nottinghamshire Healthcare NHS Foundation Trust); Porterbrook Clinic Gender Identity Service, Sheffield (Sheffield Health and Social Care NHS Foundation Trust); and West of England NHS Specialist GIC, Exeter (Devon Partnership NHS Trust). The MTSC project did not research the clinics which see only under-18s, nor those in Scotland or Northern Ireland.
} 
The group suggested how some of these barriers might be removed or mitigated:

- Increase awareness of the importance of the care the NHS is providing for trans people, and note that good spiritual care might help, for example, to decrease the suicide risk and rates of self-harm and dangerous self-medication by trans people. Show that preventative care, including spiritual care, can lead to diminishing costs in the long run.

- Utilize resources already in place, such as more general helplines provided by bodies such as Samaritans; work toward multisector and multiagency cooperation.

- Work toward resilience of services, rather than over-reliance on a few individuals and their interests.

Whilst this research group operated independently of the clinic and there was no overlap between this group and the questionnaire respondents, it is clear that there are areas of accordance between the recommendations made on the basis of their professional and personal experience, and the priority areas (positive and negative) already identified by questionnaire respondents. Although it is not possible to make statistically significant claims on the basis of these small samples, each therefore gives a snapshot of potentially more widespread experience. There are also areas of accordance with good practice identified at Sojourn Chaplaincy in California, although questions remain about how such practice might best be implemented in a socialized healthcare system. The research group's mixed status, comprising members of the trans community, academics, spiritual care professionals, and healthcare professionals with experience of working with trans people, and representing people from a range of religious traditions and none, meant that the shared values they were able to identify and the common recommendations they felt able to make carry a certain weight: this group was well aware of both the challenges facing spiritual care and its significant potential for promoting trans people's wellbeing, and these recommendations are therefore worth taking seriously.

\section{$\underline{\text { Conclusion }}$}

Healthcare chaplaincy continues to be under threat financially and conceptually. However, spiritual care for people undergoing gender transition in NHS clinics is imperative, particularly given the perception that broader spiritual provision and support for trans people are inadequate. Although they are beyond the MTSC project's remit, it will also be necessary to address trans 
people's spiritual needs in other contexts, such as elder care and dementia care ${ }^{8}$ and with children and adolescents. ${ }^{9}$ Good spiritual care, provided by chaplains and accompaniers adequately trained and resourced to help trans people find welcoming faith and peer support communities, has the potential to improve wellbeing and outcomes for a group whose mental and physical health is known often to be threatened and precarious. Those involved in trans people's healthcare at every

\begin{abstract}
${ }^{8}$ The MTSC project specifically considers spiritual care for people in the process of transition under the care of an NHS GIC. However, it is clear that much work remains to be done on supporting trans people in their interactions with GPs, acute care professionals such as accident and emergency staff, and other healthcare providers. One area likely to grow more pressing in coming years is elder care, including for those in residential homes. The National LGBT Survey 2018 found that, of trans people surveyed, the percentage of friends with whom they had been open about being LGBT increased with age, except that those in the 65+ age bracket were more likely to have been open than those in the 35-44, 45-54 and 55-64 brackets. If openness were just to do with liberalizing social attitudes and how these tend to map onto generational differences, the expectation would have been that those aged $65+$ would have been less open
\end{abstract} (Government Equalities Office 2018, 38). Shifts toward greater openness in those aged 65 and over may be attributed to factors such as death of a spouse, and/or any children's having reached adulthood, so trans individuals may feel at liberty to be open in a way they could not before because of loyalty to their families; retirement from paid employment, and therefore less fear about prejudice at work and/or economic instability as a result of openness; growing awareness of their own mortality, and a desire to deal with "unfinished business". A 2015 study noted that for older trans people with dementia, issues around gender identity could cause distress. The authors cited the case of a trans woman who had transitioned over twenty years before being diagnosed with Alzheimer's dementia: “On several occasions, however, she cheerfully referred to herself as a man. The staff at the residential home reported that [she] was displaying intermittent agitation and aggressive behaviour with no apparent triggers, but also that she had started to display a degree of stress and confusion regarding her gender. She would refer to herself with male pronouns on a semiregular basis, although without necessarily demonstrating any understanding as to what this might mean. She had also become physically and verbally upset with the fact that she was wearing female clothes on several occasions, and most recently had expressed curiosity and a degree of distress regarding her breast implants while she was being assisted with personal care by staff at the residential home" (O'Kelly, Fullick and Richards 2015, 22).

${ }^{9}$ Under-18s were outside the MTSC project's scope. However, given that the numbers referred to the Tavistock and Portman (the only NHS GIC for under-18s in England) is rising (2,016 in 2016-17, up from 97 in 2009-10 - Tavistock and Portman 2016; 2017), it seems important to ask how spiritual care might best serve this group, often assumed to lack capacity to make permanent decisions about their bodies and identities. Given that faith affiliation seems increasingly rare in younger age groups, would a chaplaincy model of care make sense to this constituency at all? 
stage, notably but not exclusively in specialist GICs, must take spiritual care seriously, aim to integrate it into holistic patient care, and seek opportunities for continuing professional development (accredited where available) on gender identity issues in healthcare.

More specifically, good spiritual care for people undergoing transition should include specialist chaplaincy services. The NHS Chaplaincy Guidelines 2015 recommend, within mental health services, "an allocation of 3.75 hours per week of chaplaincy for every 20 patients" (NHS England 2015, 18). For a GIC with 650 patients, this would mean three dedicated chaplains each working full-time - and does not take into account any chaplaincy care for patients on waiting lists. Of course, not every GIC patient will be in an "active" phase of treatment all the time; many may not need or want such intensive chaplaincy care, particularly in relation to other patients of mental health services. But this number is sobering. In reality, GICs are likely to share chaplaincy provision with other areas of their parent NHS trusts and to have a much tinier allocation (or none at all). It will therefore be necessary for GICs and their trusts to explore creatively how to commission and budget for such services, to work with those able to charge provision to directorates other than gender services so the cost is spread, and to recognize that chaplaincy is not a luxury add-on to be cut when budgets are constrained, but an expert aspect of a well-rounded care package, with the potential to alleviate mental and emotional suffering and improve outcomes. Any increase in quality provision, even if to nowhere near the levels recommended by the NHS Chaplaincy Guidelines, would therefore be an improvement. Appropriate spiritual care provision for all NHS patients is a statutory requirement and part of the NHS's own contract of care. Processes of accountability to ensure it happens are long overdue: not in order to add to the pressures of those who must make ever less money go ever further, but because spiritual care itself has the potential to improve outcomes and increase wellbeing. For patients of gender medicine services, who may experience particularly acute spiritual distress, or have particularly long waiting times, good spiritual care - including chaplaincy care - is especially pressing.

\section{Works cited}

Archbishops' Council. (2003). Some Issues in Human Sexuality: A Guide to the Debate. London: Church House Publishing. 
Beardsley, Christina. (2018). A Vicar's Story. In: Christine Burns (ed.). Trans Britain: Our Journey from the Shadows. London: Unbound.

Berry, Wendell. (2002). The Art of the Commonplace: The Agrarian Essays of Wendell Berry. Berkeley, CA: Counterpoint.

Cambridge Festival of Ideas. (2015). "Speaker Spotlight: Reverend Dr Christina Beardsley." https://www.festivalofideas.cam.ac.uk/speaker-spotlight-reverend-dr-christina-beardsley

Clucas, Rob. (2018). The Church of England: Welcoming Transgender People? http://modernchurch.org.uk/downloads/send/32-articles/893-cofe-welcome-trans

Cinnamon Network. (2018). The Church's Impact on Health and Care, Version 05/18,.http://www.cinnamonnetwork.co.uk/wp-content/uploads/2018/06/3-Cinnamon-

Health-Research-Latest.pdf

Davie, Grace. (2012). A European Perspective on Religion and Welfare: Contrasts and Commonalities. Social Policy and Society 11(4) pp.989-999.

Davie, Grace. (2015). Welfare and Religion in Europe: Making the Connections. Theology 118(1) pp.10-17.

Government Equalities Office. (2018). National LGBT Survey Research Report July 2018. Manchester: Department for Education.

Haas, Ann, Philip Rodgers and Jody Herman. (2014). Suicide Attempts Among Transgender and Gender Non-Conforming Adults: Findings of the National Transgender Discrimination Survey. American Foundation for Suicide Prevention and University of California School of Law. http://williamsinstitute.law.ucla.edu/wp-content/uploads/AFSP-Williams-Suicide-Report-

Final.pdf

Hancocks, Graeme, John Sherbourne and Christopher Swift. (2008) 'Are They Refugees?' Why Church of England Male Clergy Enter Healthcare Chaplaincy. Practical Theology 1(2) pp.163-179.

Healthwatch. (2015). Action Needed on Gender Reassignment Surgery Delays. http://www.healthwatch.co.uk/news/people-facing-unacceptable-waits-gender-reassignmentsurgery

House of Bishops. (2018). An Update on 'Welcoming Transgender People' (GS Misc 1178). https://www.churchofengland.org/sites/default/files/2018-01/GS\%20Misc\%201178\%20-

$\% 20 \mathrm{An} \% 20$ update $\% 20$ on $\% 20$ Welcoming $\% 20$ Transgender $\% 20$ People.pdf

Hudson-Sharp, Nathan and Hilary Metcalf. (2016). Inequality Among Lesbian, Gay, Bisexual and Transgender Groups in the UK: A Review of Evidence. London: National Institute of Economic and Social Research

McNeil, Jay, Louis Bailey, Sonja Ellis, James Morton and Maeve Regan. (2012). Trans Mental Health Study 2012. Edinburgh: Scottish Transgender Alliance. https://www.scottishtrans.org/wpcontent/uploads/2013/03/trans_mh_study.pdf 
McSherry, Wilfred. (2007). The Meaning of Spirituality and Spiritual Care within Nursing and Health Care Practice. Wiltshire: Quay Books.

McSherry, Wilfred. (2010). Spiritual Assessment: Definition, Categorisation and Features. In: Wilfred McSherry and Linda Ross (eds.). Spiritual Assessment in Healthcare Practice. Keswick: M\&K Publishing. pp.57-78.

NHS England (2015). NHS Chaplaincy Guidelines 2015: Promoting Excellence in Pastoral, Spiritual and Religious Care. https://www.england.nhs.uk/wp-content/uploads/2015/03/nhs-chaplaincyguidelines-2015.pdf

NHS England (2018). NHS Standard Contract 2017/19 and 2018/19 Service Conditions (Full Length), May 2018 edition. https://www.england.nhs.uk/wp-content/uploads/2018/05/2-nhs-standardcontract-2017-19-particulars-service-conditions-may-2018.pdf

O'Kelly, Allison, William Fullick and Giles Richards. (2015). Out of the Closet, Into a Difficult Place in Later Life. Journal of Dementia Care 23(3) pp.22-24.

Simmons, David. (2018). 'Now Someone Knows My Name': A Study of Church-led Projects in Assisting Health Outcomes. http://www.cinnamonnetwork.co.uk/wpcontent/uploads/2018/05/Cinnamon-Health-Research-Article.pdf

Slawson, Nicola. (2018). Faith-Based Groups 'Increasingly Stepping in to Plug Gaps in NHS'. The Guardian, 30 May 2018. https://www.theguardian.com/society/2018/may/30/faith-basedgroups-increasingly-stepping-in-plug-gaps-nhs

Sojourn Chaplaincy. (2017). Trans Spiritual Care Initiative. http:// sojournchaplaincy.org/?p=380

Swift, Christopher. (2014). Hospital Chaplaincy in the Twenty-First Century: The Crisis of Spiritual Care on the NHS ( $2^{\text {nd }}$ ed). Aldershot: Ashgate.

Swift, Christopher. (2015). Health Care Chaplaincy. In: Christopher Swift, Mark Cobb and Andrew Todd (eds.). A Handbook of Chaplaincy Studies: Understanding Spiritual Care in Public Places. Abingdon: Routledge. pp.163-174.

Swinton, John. (2001). Spirituality and Mental Health Care: Rediscovering a "Forgotten" Dimension. London: Jessica Kingsley.

Swinton, John and Ewan Kelly. (2015). Contextual Issues: Health and Healing. In: Christopher Swift, Mark Cobb and Andrew Todd (eds.). A Handbook of Chaplaincy Studies: Understanding Spiritual Care in Public Places. Abingdon: Routledge. pp.175-185.

Tavistock and Portman NHS Trust. (2016). Gender Identity Development Service Statistics. https://tavistockandportman.nhs.uk/documents/408/gids-service-statistics.pdf

Tavistock and Portman NHS Trust. (2017). GIDS Referrals Increase Slows in 2016/17. https://tavistockandportman.nhs.uk/about-us/news/stories/gids-referrals-increase-slows201617/

Yarhouse, Mark. (2015). Understanding Gender Dysphoria: Navigating Transgender Issues in a Changing Culture. Downers Grove, IL: InterVarsity Press. 
Post-print: Accepted for publication in Health and Social Care Chaplaincy 